\title{
Smart Festivals? Security and Freedom for Well-Being in Urban Smart Spaces
}

\section{Introduction: the problem for smart cities}

Smart City innovations promise much in the way of improved efficiency, reliability and real-time optimization of resources (Townsend 2013). City governments will spend an estimated \$135 billion on smart city innovations by 2021 (International Data Corporation 2018). An essential selling point of the Smart City is surveillance of both citizens and the environment (including the workplace and smart homes) to promote well-being, a sense of security, real-time governance and citizen-centricity (Cardullo and Kitchin 2018, Kitchin 2014). To this end, a smart city resident may be subject to mass surveillance via CCTV, automatic facial recognition at smart border crossings (e.g., Ireland-Northern Ireland, US-Mexico), and corporate collection of personal data such as geolocational tracking.

The touted benefits of surveillance may bring unintended consequences. In this paper we examine "surveillance anxiety", a purported reaction to these measures. Is there evidence to suggest that increased presence of surveillance measures are unwelcome? To address this, we focused on the dynamic community of the summer festival. We report a survey conducted on attitudes and behaviors to music festivals. Music festivals serve as a natural lab, which have recently had to grapple with a number of high-profile incidents (e.g., the 2017 Las Vegas shooting, a drug overdose death in 2014 at Coachella, and widespread sexual assaults and harassment) resulting in the rapid introduction of smart surveillance technology into formerly less-policed spaces. We asked participants to comment on their safety concerns and what measures make them feel safer. Unsurprisingly, females and non-binary individuals had more safety concerns than males, who were more concerned about crowd violence rather than individual assaults. More importantly, unwanted security was a common safety concern across all demographics. How can these findings be used to inform planning the smart city?

\section{Surveillance anxiety}

The concept of surveillance anxiety refers to acute persistent worry and stress experienced by individuals and groups as a result of known or suspected surveillance. A critical component is that the subject of surveillance experiences inflated worries about how they are being judged, 
and that this judgement will be either exploitative and/or derogatory. Surveillance anxiety has been proposed in two different contexts: mass surveillance in public spaces and in healthcare. In both cases surveillance anxiety is proposed to emerge when subjects are aware of surveillance (Minton 2013, McGowan 2016). Because surveillance anxiety is conceptualized as awareness of surveillance, there need not be actually occurring surveillance for it to manifest.

Although there are many studies on the impact of surveillance on crime activity, dating to social reformers such as Jeremy Bentham and the panopticon (Bentham 1995), there is relatively little work on how surveillance affects fear and anxiety in non-criminal situations. Minton provides data from a field study to suggest that whereas neighborhood residents may initially desire increased CCTV surveillance of their homes by a security company, over time, they reported little benefit from it and experienced increased worry about their privacy. As one resident of the survey site stated:

When I see the CCTV, I still don't feel safe, in fact sometimes it makes me feel more anxious. Because I think I'm in a bad area, I get into a panic sometimes because, for one, you're not sure the cameras are working. You see them and you see a lot of them highly visible and it just makes me feel scared. It doesn't have the effect of making me feel safe, it raises emotions of feeling frightened and intimidated (Minton 2013, 12).

Visible security (chain link fences, warning notices, “smart water,” gated access, CCTV) has been found to make people feel less safe (Gill, Bryan and Allen 2007). In a major survey of crime fear levels in Glasgow, Ditton (2000) found majority support for new CCTV installation in residential areas, but no decrease in fear levels after installation, while other studies have found that better street lighting is more cost effective than CCTV (Lawson, Rogerson and Barnacle 2018).

One aspect of modern capitalism is the increasing pressure that individuals are under to be seen to conduct themselves appropriately. Examples of such "surveillance capitalism" include health apps, Wi-Fi-connected CPAP machines and heart monitors that produce responsibilized behaviors such as required daily steps or heart rates, rewarded with lower insurance premiums or workplace wellness accreditation (Zuboff 2019, Allen 2018). Over-frequent health checks can exacerbate feelings of guilt and worry (Stol, Schermer and Asscher 2017). Some psychoanalytic literature has suggested that there are mental health costs to living under conditions of 
heightened surveillance (McGowan 2016). Here, a private subject fantasizes that they could, if only surveillance were not so obtrusive, truly be themselves. The lack of opportunity to do so, however, causes distress: it is not just the fact of surveillance that matters, but the creation of an unobtainable subjectivity promised by surveillance that is stressful. Privatization of formerly public spaces (and the security surveillance it entails) has also been frequently cited as a major factor of modern capitalism (Minton 2018).

Surveillance anxiety came to the public's notice in the wake of a testimony-based report on "living under drones." Residents of Pakistani border areas targeted by US drones reported anguish and trauma in addition to death and property destruction. As the report put it, the presence of drones:

terrorizes men, women, and children, giving rise to anxiety and psychological trauma among civilian communities. Those living under drones have to face the constant worry that a deadly strike may be fired at any moment, and the knowledge that they are powerless to protect themselves (Cavallaro, Sonnenberg and Knuckey 2012, vii).

As concerning as these examples are, there is little empirical evidence to support or refute it in everyday life. However, if it does exist, surveillance anxiety likely will be experienced inequitably because people of color, people in poverty, LGBTQ+ and in urban areas experience disproportionately higher levels of surveillance. For example, in-depth case studies of digital surveillance of the poor has instituted a new regime of the "digital poorhouse" (Eubanks 2018). People of color are disproportionately represented in police databases, and consequently algorithms built to assess re-offense likelihood discriminated against them (Angwin et al. 2016). Analysis of over 60 million stop and searches across 20 states revealed that black drivers were stopped more often than whites, and that Hispanic drivers were stopped less often (Pierson et al. 2017). They concluded "the bar for searching black and Hispanic drivers is lower than for searching white drivers in nearly every location” $(2017,11)$.

Surveillance is also more preponderant in urban than rural areas, and since urban areas are typically more diverse this will result in higher surveillance of minorities. As such, urban music is often the locus of social commentary on and protest of excessive surveillance. For example, the Grime scene in the East End of London arose due to a variety of socio-cultural factors, mainly socio-economic marginalization and the poor quality of life in East London council 
estates. Hancox has argued that Grime should be understood against a larger background of gentrification and urban development, reducing the spaces where Grime is produced and subjecting them to surveillance (Hancox 2018). Grime addresses the criminalization of members of these communities by the London Metropolitan Police through monitoring and surveillance (Fatsis 2018), where the influence of the police on quality of life and the public identity of black youth is felt in lyrics such as "It was only yesterday, there was less bobbies on the beat" [Dizzie Rascal's Sittin Here (Boy in Da Corner)] and “Out there tryna survive on the streets / Tryin’ not to get killed by the police [Skepta's Man (Konnichiwa)].

In the health profession, surveillance anxiety has been studied in relation to psychological wellbeing in patients diagnosed with diseases such as prostate cancer. In cases of low-risk cancer, patients are placed on "active surveillance" (AS) or regular check-ups and scans. Significant but widely varying reports suggest that men-between 10-50 percent according to some estimates (Dall'Era et al. 2008) and 5-13 percent of men according to a more recent study (Marzouk et al. 2018) - terminate AS and undergo surgery due to cancer-related anxiety despite lack of evidence for disease progression. Although surgery carries risks of erectile dysfunction and urinary incontinence, these patients prefer surgery to continuing surveillance. The main cited causes of anxiety under AS are feeling a loss of control and uncertainty over the future. However, we still know little on how termination of active surveillance correlates with demographics such as age or race, or how AS affects well-being.

Well-being is increasingly promoted as a better index "beyond the GNP" of national and global health (OECD 2017). Using 50 indicators of well-being the United Nations assessed less tangible measures such as happiness and life satisfaction across 41 countries. Major challenges include inequalities in well-being, migrant well-being, and the obligation of public institutions to create the conditions for well-being. Many adults identify lack of control over governance as a key issue with only one in three adults believing they have a say in what government does (OECD 2017). Although holistic approaches that integrate psychological health into measures of wellbeing are becoming more common, there is still little standardization across mental health services to collect these data (Connell, O'Cathain and Brazier 2014). Despite the importance of mental health, it is concerning that disorders are rising in western industrialized nations (Ohrnberger, Fichera and Sutton 2017). Although physical and mental health complement each 
other they are too often separated in the medical profession and public health (Ohrnberger et al. 2017, Kilbourne et al. 2018). Further, ample data have demonstrated that psycho-social stresses are embodied, and there is demographic disparity in exposure and vulnerability to stresses. Anxiety is manifest biologically as a deregulated hypothalamic-pituitary-adrenal (HPA) axis (Schulkin, Gold and McEwen 1998) which controls the stress response. Deregulation of HPA results in elevated cortisol levels_-either chronic or several acute episodes, both of which contribute to cumulative stress burden—which will damage soft tissues and impedes immune functioning with a long-term outcome of higher morbidity, higher mortality, and reduced life span. The end result is a weakened immune response (greater morbidity) and shortened life span (increased mortality) (Goosby, Cheadle and Mitchell 2018). Stress burden is socially patterned with minorities bearing greater loads than whites and females bearing greater loads than males.

\section{Why festivals?}

Festivals were chosen as a natural field lab for studying the affective relationship between citizens and surveillance, with results applicable to other smart spaces. In referring to the festival as a natural field lab, we point to the real-world and authentic nature of the festival setting and the lack of control over variables that alter the festival experience. The field setting provides a representative environment (List John 2007) and a natural, rather than self-selected or convenient sample of research (Arnett 2008, Henrich, Heine and Norenzayan 2010, Smith and Little 2018). Thus, given the rapidly changing surveillance environment at festivals, we propose that they can be used as key risk indicators for slower, more long-term changes in surveillance in urban areas. Our fundamental question is whether surveillance measures have been noticed by attendees, and has this affected their festival-going experience, that is, their participation in this community?

The modern music festival is perhaps most associated in the public mind with Woodstock (first held in 1969) and Glastonbury (first held 1970). More recently, the Burning Man festival (first held in 1986 in San Francisco and in the desert since 1991) has attracted participants from around the world. Burning Man is especially notable for attracting a wide diversity of "free spirits” originally loosely affiliated with the San Francisco Cacophony Society, an inspiration behind Fight Club, as well as urban exploration and flash mobs. There are now dozens of Burning Man events in the United States, as well as in Europe, South Africa and Australasia. 
Festivals are a particularly important type of event because they promise to provide a “transformative” (as Burning Man advertises itself) or liminal space. As with tourist sites, they are constructed as symbolic opposites of everyday life (Knudsen, Rickly and Vidon 2016). Festivals promise an experience of authenticity. That this authenticity is itself a fantasy, does not mean that the experience is empty—fantasy does important work. In festivals, attendees have traditionally been able to act out, disrupt day/night sleeping schedules, indulge in illicit substances or experience new sexual liaisons.

Over the past few years however, festivals have experienced a sharp increase in assaults, pickpockets, drug overdoses, and gun violence. A June 2018 Yougov survey in the UK revealed that 43 percent of women have experienced unwanted sexual behavior at festivals, but that fewer than 2 percent were reported (Snapes 2018). The OurMusicMyBody campaign in Chicago (which hosts Lollapolooza) has advocated for festivals to implement preventative strategies. Similar campaigns have been launched in the UK (Safe Gigs for Women) and Australia (Your Choice). In response, in 2018 Coachella implemented surveillance of the perimeter by drone in the wake of the mass shooting at the Las Vegas Route 91 music festival, in which 51 people were killed and over 800 injured. In 2015 Leicester (UK) police scanned the 90,000 attendees at the Download Festival and checked them against criminal databases with automated facial recognition technology (FRT) (BBC 2015). The technology was used at the Notting Hill Carnival in 2016-17 but after controversy over its efficacy was replaced in 2018 by "super recognisers" and "knife arches” (walk-through metal detectors).

Festivals also illustrate another trend in which surveillance is marketed as entertainment. Music festivals have invested in new technologies that enable both the intensification of surveillance while also presenting an aesthetic of enjoyment. For example, Sendrato has developed a wearable wristband for festivals that can be used for entertainment. The wristband, recently used at Tomorrowland in Belgium, uses RFID with built-in LED lights that allow festival organizers to synchronize their access and crowd control protocols, brand activation, and audience engagement. Upon entry, guests are tagged and monitored throughout their attendance allowing location analytics to be used to measure footfall and heatmap audience movements for risk management, while its built-in lighting can be synchronized with specific performances to create massive light shows across the crowd. Consumer products such as LynQ allows users to locate 
others through real-time distance and direction tracking via a wearable device that can be useful for finding a friend in large crowds or where cell-phone coverage is limited or non-existent (such as at Burning Man).

Festivals and police have experimented with using facial recognition technology for security and access control. At a 2018 music concert in China authorities used facial recognition to catch a fugitive wanted for “economic crimes” who was identified out of a crowd of 50,000 (Deahl 2018). Concert organizers have also begun to experiment with using facial recognition. Ticketmaster, for example, is partnering with biometric identification firm Blink Identity to embed biometric data in tickets in order to reduce ticket scalping (Holbrook 2018).

These speculative surveillance futures suggest several key patterns that may define how festival landscapes are experienced and governed, and by extension the governance of smart spaces. We emphasize four developments. First, it suggests the intensification and normalization of increasingly pervasive and ubiquitous forms of surveillance and data analytics. It may soon become impossible to escape biometric observation in order to access a public space, whether by digital face capture, body-tagging by wristband or chip implantation (as has occurred for at least 4,000 people in Sweden (see (Savage 2018), or geolocational tracking and body movement (gestures, gait analysis, posture). Second, the intensification is further compounded by security and marketing logics that mutually reinforce a broader strategy of crowd control along political and economic lines. Third, leading-edge biometric technologies promise to infer not just identity (who someone is) but also what someone is; for example gay or straight (Wang and Kosinski 2018), and law abiding or criminal (Wu and Zhang 2017). Finally, these logics of control fundamentally depend on surveillance strategies that invest in the power of the corporeal body to serve as both the object for governance, but also as subject for enabling new forms of audience engagement and affective atmospheres. This is particularly evident in the case of wearable technologies that can be exploited to encourage audience engagement with branded spaces for social media marketing.

We propose that festivals are an ideal setting to study how surveillance alters affective relationships to the surveilled environment for two reasons. First, festivals serve as a liminal space, a temporary escape from the constraints of everyday life and venue for behavioral experimentation (Kim and Jamal 2007). The festival experience (commercially aimed at a 
particular demographic market) is one that is co-created by organizers and festival goers which allows for the creation of an authentic experience relative to the socio-spatial venue (Szmigin et al. 2017). In other words, the ethos or vibe of a festival is as much produced by the marketing of the festival to a demographic sector and by the attendees themselves. Second, festivals are shortterm events that occur annually. Introduction of surveillance measures, unlike in a public space, are dramatic. In a city, the gradual introduction and escalation of surveillance tools is experienced over longer periods of time. In a festival setting, the comparative experience between two festivals events where drones and extra security personnel have been introduced is striking (Winton 2018) and we may better capture the primary affective reaction to changes in surveillance. While festivals attracted a wide range of people across the demographic spectrum, they tend to have a larger youth following. Understanding how younger generations, in particular, feel about surveillance is a critical need because they are much more accustomed to being observed (both posting to and being tagged in various forms of open social media) and have been surveilled in public for more, if not, most of their lives.

\section{Festival Survey}

To generate pilot data on whether the introduction of surveillance is perceived as a negative experience (does not address or reduce safety concerns/does induce surveillance anxiety), we conducted an online survey designed to capture affective responses to the introduction of surveillance to festival environments. The survey was hosted on Survey Monkey. We did not request or record any personal identifying information, such as email addresses or names. As such, all data are fully anonymized and cannot be linked to an individual. Sample size per question varies depending on participant choice, with a total $n=201$ and individual questions either $n=200$ or $n=201$. Full survey results are presented elsewhere (Author 2018) but, here, we present the responses to four questions that focus on adult $(>18)$ festival-goer attitudes about safety and security (Table 1). For gender, non-binary is an umbrella term for intersex, trans, and non-binary because participants all chose non-binary in addition to other responses-e.g., those choosing trans also chose non-binary.

Table 1: Demographic data

\begin{tabular}{lccccccc}
\hline & $\mathbf{1 8 - 2 4}$ & $\mathbf{2 5 - 3 4}$ & $\mathbf{3 5 - 4 4}$ & $\mathbf{4 5 - 5 4}$ & $\mathbf{5 5 - 6 4}$ & $\mathbf{6 5 +}$ & Total \\
Female & 28 & 19 & 13 & 9 & 2 & 1 & 72 \\
Male & 25 & 33 & 25 & 22 & 13 & 1 & 119
\end{tabular}




\begin{tabular}{lccccccc} 
Non-binary & 4 & 2 & 2 & 1 & & & 9 \\
Total & 57 & 54 & 40 & 32 & 15 & 2 & $\mathbf{2 0 0}$ \\
\hline
\end{tabular}

We asked participants ( $\mathrm{n}=201$ ) why they attend festivals (for full results see (Author 2018). The primary reason is for the live music - female and non-binary participants ranked this first more consistently than males and non-binary participants. The lowest ranked response was to "indulge in substances" - broken down demographically, however, males rated ranked substance indulgence equal to "rules-free zone" (the second lowest choice) while females and non-binary ranked "indulge in substances" consistently low. This result is worth underlining because it differs from the literature on festivals as a method of escaping the constraints of everyday life and the media emphasis on drug overdose risk (Szmigin et al. 2017, Kim and Jamal 2007).

Festival Personal Safety Concerns. Participants were asked to select but not rank their personal safety concerns from a list and, if they had ones not listed, they were asked to describe them. Figure 1 shows the list of choices and the percentage of the sample choosing each item. The highest concern is crowd violence (71 percent), followed by unwanted security (47 percent). This is interesting in light of the low rank for a "rules-free" zone discussed above. While nearly half the participants fear unwanted security, they do not associate that with fewer rules/constraints. Perhaps there is a tacit understanding that festivals provide a liminal space so festival-goers do not rank that reason high since they assume festivals, by rule, are outside the bounds of daily life. Concerns over sexual harassment and sexual assault are identified by about 1 in 4 participants, but much lower than the two top concerns. 


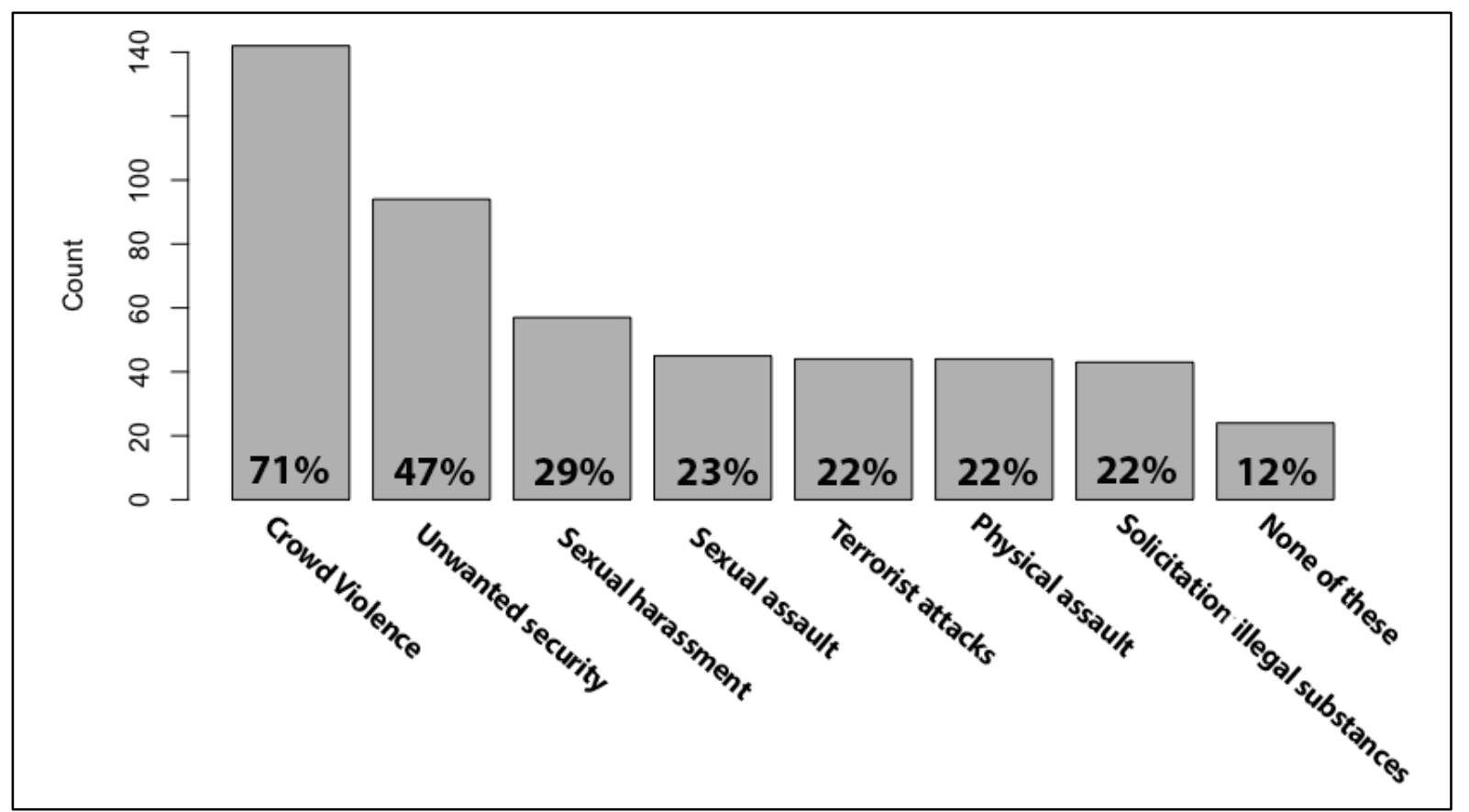

Figure 1. Safety concerns. Count and percentage choosing each option (participants could select more than one option). $n=201$

Females and non-binary people reported more concerns than males (Figure 2). The two most commonly reported concerns for males were crowd violence (54 percent) and unwanted security (47 percent). Every female respondent reported a concern about crowd violence (100 percent) followed by an equal concern for unwanted security (47 percent) and sex-related incidences. By contrast, males reported very little fear over sexual harassment or assault (13\% compared to 51\% for females and 56\% for non-binary). One male wrote: “Im [sic] not personally worried about sexual assault. I am nervous for my female friends.” Twenty-eight participants wrote-in additional safety concerns (15 males, 12 females, and 1 non-binary). Putting aside idiosyncratic concerns ("being hit by flying bottles of urine"), theft was the biggest write-in (n=8) with more males expressing this concern $(n=6)$. Only two males were concerned over security whereas four females were with specific mentions of abuse of power. More females than males expressed concerns about substance abuse ruining the festival and equal numbers were concerned about crowd crushing. 


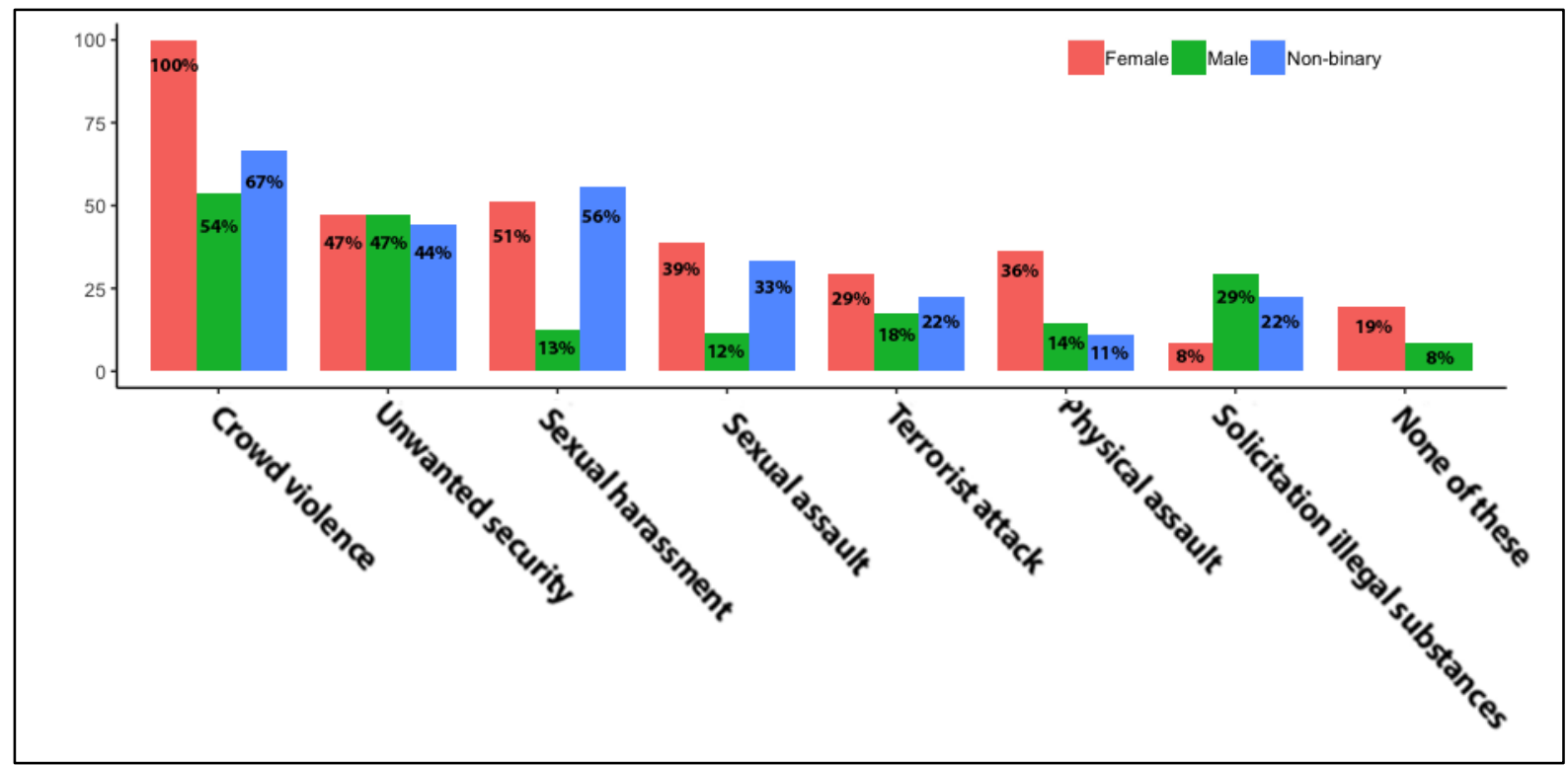

Figure 2: Safety concerns by sex/gender. $\mathrm{N}=201$

Safety measures taken by festival-goers or implemented at festivals. Participants were asked to select any options that made them feel safer at a festival and to write-in additional measures not listed (Figure 3). Going with friends and the availability of health tents rated highly in all demographic categories. One-hundred percent of non-binary participants felt surveillance did not make them safer and only a small number of men felt surveillance made them feel safer (13 percent) compared with 33 percent of females. Females chose going with friends first and health tents second. Non-binary chose going with friends first and venue location second. More males chose health tents first and going with friends second. Females felt consistently safer with any measure compared to males and non-binary, with the exception of venue location. Generally, security in the form of surveillance, police, or private security were the least popular choices for effective safety measures. Measures that helped participants feel safe were crowd-sourced (citizen security, health tents), having a support network, and the festival itself (venue and ethos). Three females and five males wrote in additional measures but these were variants on listed choices (e.g., “medical facilities on site,” festival tradition, metal detectors). One person called for drug testing and two had specific comments on the police. One felt divided because having police to report sexual harassment was preferred but the participant did not feel the police could do anything after the fact. Another person specifically stated that private security forces were dangerous - “....they seem to feel entitled and that they just have a status/a power over you.” 


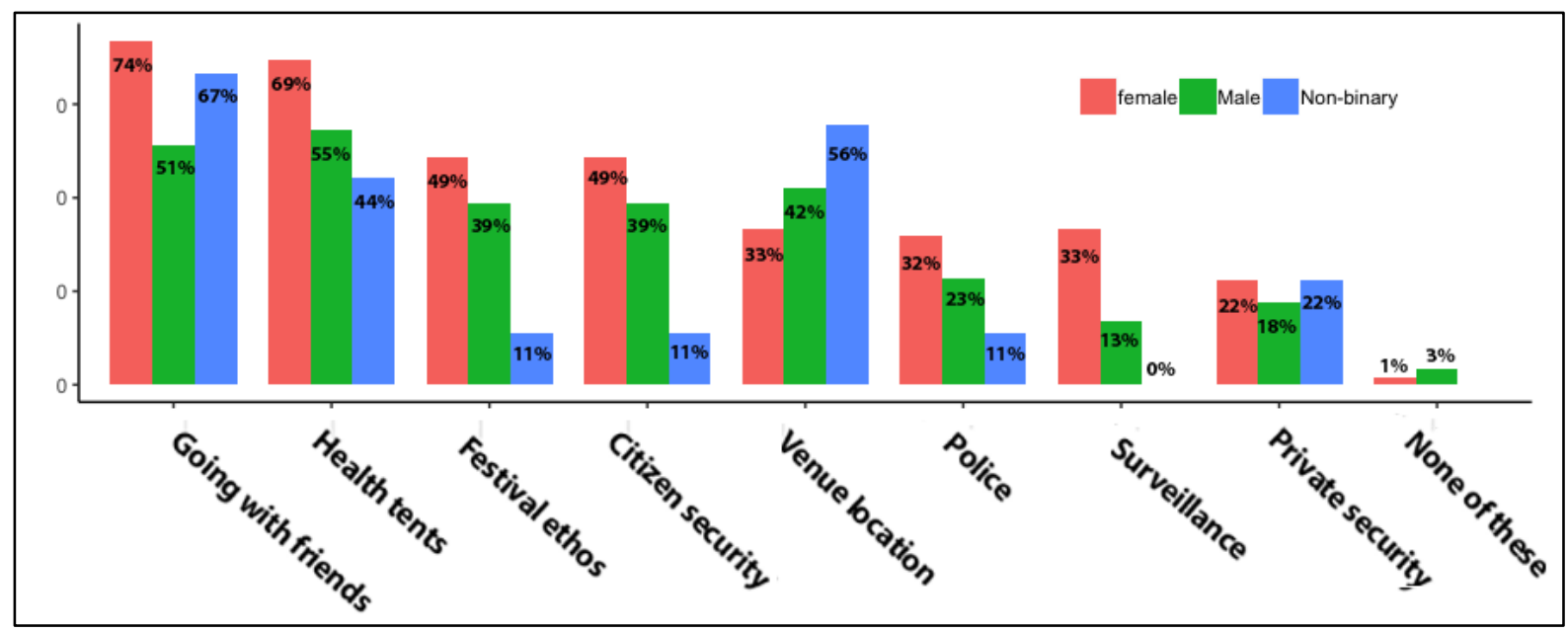

Figure 3: Safety measures by sex/gender. $n=199$

Attitude towards surveillance/security measures at festivals. Non-binary participants continue to exhibit a mistrust of authority by rating the presence of surveillance/security measures as negative (Figure 4). Most people feel it changes the vibe and makes them conscious of being watched. Few participants felt these measures made them feel unsafe but the responses indicate they are unwanted. Females and non-binary participants were very split on the issue with some saying they felt they were at risk from authorities and others saying it made them feel safer. More males reported feeling indifferent to these measures (34 percent compared to 26 and 22 for female and non-binary, respectively)

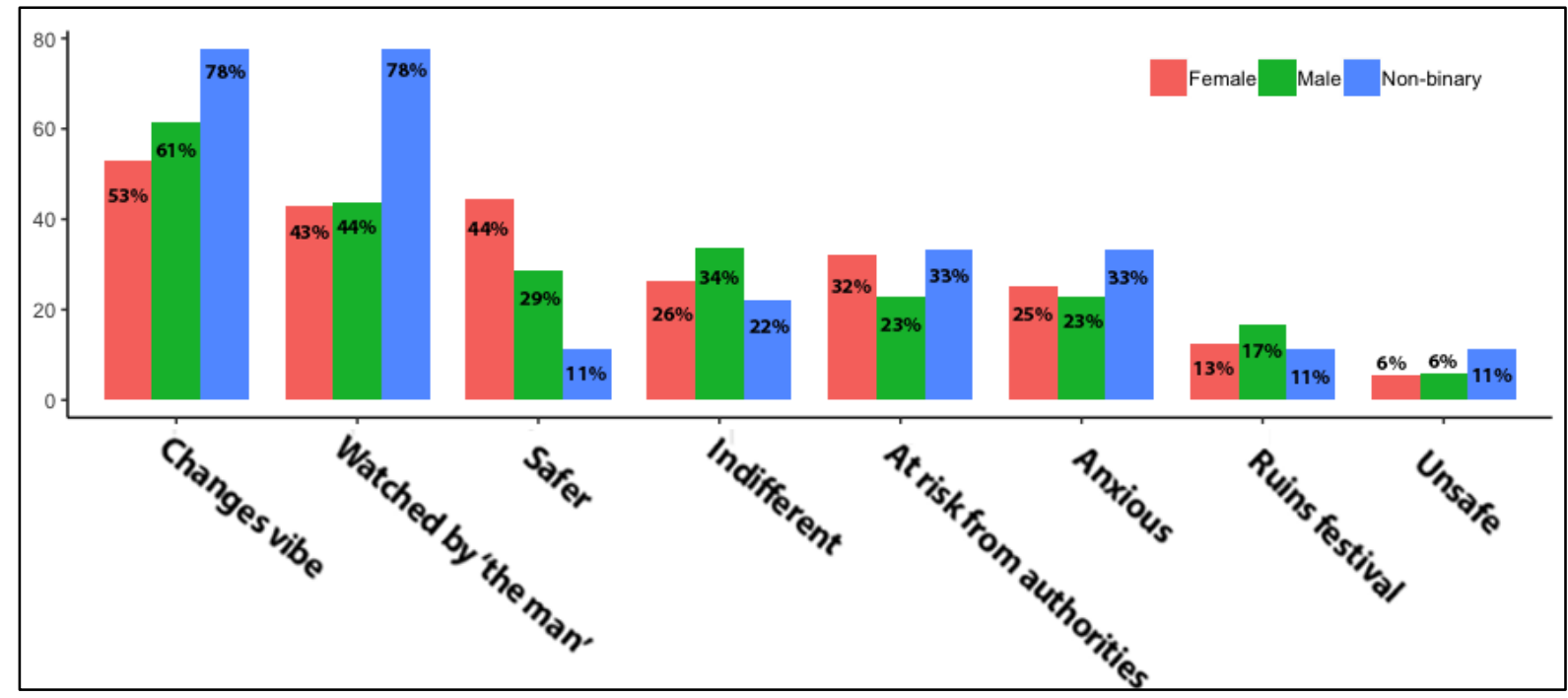

Figure 4: Attitude toward surveillance/security measures at festivals. $\mathbf{n = 2 0 0}$ 


\section{Discussion}

Our survey results suggest a mixed attitude about various forms of security. Contrary to our initial expectations from the literature, festival-goers do not rank the liminality of a festival or escapism as primary reasons for attending. There is also an overall negative attitude about security that emerged across responses. As mentioned above, there may be an assumption that festivals provide that liminal space where normal social rules are absent. Certainly, write-in responses often focused on the hope that people over-indulging (either friends or strangers) did not interfere with their enjoyment of the event. And responses across questions indicate a strong preference for community-based safety measures-being with a group, having a health tent, and citizen security. There were specific concerns voiced by females that they might be harmed by figures of authority while at the same time they expressed some element of feeling safer with security present-this contrast may reflect the particular concerns of females over sexual infractions. Finally, we found that between 1 in 4 (men and women) and 1 in 3 (non-binary) respondents reported feeling explicitly anxious about surveillance.

Although there is still much work to be done on elucidating when and if surveillance anxiety is a persistent factor of the smarty city in the age of the Internet of Things, our pilot survey does provide indicators for preliminary conclusions that can inform planning for the smart city. First, it is notable that discomfort for security surveillance was a consistent factor among the majority (but not all) of the respondents. This is quite remarkable, given the youth of our respondents (median age <35). This means they came of age during the advent of social media and the rollout of governmental security measures (September 11, 2001 occurred 17 years prior to our survey) and as such may be expected to be inured to having open, digitally documented lives. And yet respondents not only disliked surveillance, but felt that policing, private security and surveillance negatively contributed to security. One third of respondents expressed anxiety about surveillance, and slightly more felt “at risk” from the authorities.

Second, security and surveillance were experienced very differently by respondents. Perhaps the most suggestive here are the different concerns about being “watched by the man” as our survey put it. Whereas nearly 4/5ths of those identifying as non-binary identified this authoritative surveillance as a concern, fewer than half of men and women did. Planners of the smart city would do well to recall this concern felt by minorities. Another difference, not exclusive to 
festival spaces, are fears of sexual harassment. Only about 1 in 10 men feared this, whereas nearly half of women and 1 in 3 non-binary did. We can speculate that if the smart city credibly planned surveillance around preventing sexual harassment it would be much more likely trusted.

Third, measures that are within the control of the community such as "going with friends," "health tents" and "festival ethos" were all deemed to be the best way to enhance well-being, especially for women. This finding is in stark contrast to outsider-imposed security (surveillance or policing). Not a single non-binary respondent identified surveillance as a contributor to safety, and given that the biggest concern overall is "crowd violence" which can be considered an internally-generated problem, it is reasonable that respondents should feel that preventative measures should also be within the control of the community. Although more work needs to be done here we can tentatively conclude that planning and designing the smart city will be more successful if it is not top-down, but is "co-created" with residents.

Finally, we point to our finding that crowd violence is the biggest single concern (and the only concern felt by a majority of men). The proliferation of unrest and protest in cities dating to the 1960s and the Watts Riots, often in association with police use of deadly force, is patently a massive concern. According to the crowdsourced project Mapping Police Violence, over 1,000 people were killed in the US by police in each of the last several years disproportionately affecting African-American and Hispanics people (Mapping Police Violence 2018). Although very few people are shot by police in the UK, a parallel concern is inequitable stop and search procedures. The biggest urban riots in the UK since the war occurred in 2011 following a police shooting. Although the UK Conservative government attributed the cause to criminal behavior, the only post-hoc report which interviewed participants found a variety of contributory causes including perceived social injustices and frustration at the way communities were policed (Lewis et al. 2011). Although we do not know how much excessive surveillance in those communities played a contributory role to those feelings, interviewees reported being stopped and searched at disproportionate levels (black people were 2.5 times more likely to be stopped and searched). It is worth noting that rioting in Brixton, London followed the "Splash" music festival. According to media reports the mood of this crowd "changed dramatically" (Taylor 2011) at a certain moment. How and why this change occurred is not well understood (one suggestion is excessive 
policing at the festival), but the possibility that a big group of people will exhibit violence remains a significant concern among our respondents.

An important debate in smart city surveillance seeks to understand the conditions that legitimate smart cities by critically unpacking their claims. Our research contributes to that debate by raising key concerns about the normalization of smart logics and technologies in urban governance through the surveilled citizen. Utopian discourses of smart cities may act to reproduce existing inequalities, digital divides, and power structures, as well as to register increased burdens on well-being, both physically and mentally. Although a significant proportion of our respondents reported they experience surveillance anxiety, we still know too little about its prevalence over the long-term, who is more likely to experience it, and under what conditions. Given the foundational basis of surveillance in enabling the smart city to function, it will be important to further elucidate these questions.

\section{Acknowledgements}

\section{References}

Allen, M. 2018. You Snooze, You Lose: Insurers Make The Old Adage Literally True. ProPublica Nov 21. https://www.propublica.org/article/you-snooze-you-lose-insurers-make-the-old-adageliterally-true (last accessed 21 November 2018).

Angwin, J., J. Larson, S. Mattu \& L. Kirchner. 2016. Machine Bias. ProPublica May 23. https://tinyurl.com/jzdpyz (last accessed May 27, 2016).

Arnett, J. J. 2008. The neglected 95\%: why American psychology needs to become less American. American Psychologist, 63, 602-14.

Author. 2018. An Empirical Study of Suveillance Anxiety socARXIV.

BBC, T. 2015. Facewatch "thief recognition" CCTV on trial in UK stores. The BBC. https://www.bbc.com/news/technology-35111363 (last accessed November 15, 2018).

Bentham, J. 1995. The Panopticon writings. London, New York: Verso.

Cardullo, P. \& R. Kitchin. 2018. Being a 'citizen' in the smart city: up and down the scaffold of smart citizen participation in Dublin, Ireland. GeoJournal, Online first, 1-13. 
Cavallaro, J., S. Sonnenberg \& S. Knuckey. 2012. Living Under Drones: Death, Injury and Trauma to Civilians from US Drone Practices in Pakistan. Stanford; New York: International Human Rights and Conflict Resolution Clinic, Stanford Law School; NYU School of Law, Global Justice Clinic.

Connell, J., A. O'Cathain \& J. Brazier. 2014. Measuring quality of life in mental health: are we asking the right questions? Social science \& medicine (1982), 120, 12-20.

Dall'Era, M. A., M. R. Cooperberg, J. M. Chan, B. J. Davies, P. C. Albertsen, L. H. Klotz, C. A. Warlick, L. Holmberg, D. E. Bailey, M. E. Wallace, P. W. Kantoff \& P. R. Carroll. 2008. Active surveillance for early-stage prostate cancer. Cancer, 112, 1650-1659.

Deahl, D. 2018. Suspect caught in China at music concert after being detected by facial recognition technology. The Verge April 12. https://www.theverge.com/2018/4/12/17229530/china-facialrecognition-technology-suspect-music-festival (last accessed November 15, 2018).

Ditton, J. 2000. Crime and the City. The British Journal of Criminology, 40, 692-709.

Eubanks, V. 2018. Automating inequality : how high-tech tools profile, police, and punish the poor. New York: St. Martin's Press.

Fatsis, L. 2018. Grime: Criminal subculture or public counterculture? A critical investigation into the criminalization of Black musical subcultures in the UK. Crime, Media, Culture, 1741659018784111.

Gill, M., J. Bryan \& J. Allen. 2007. Public Perceptions of CCTV in Residential Areas: "It Is Not As Good As We Thought It Would Be”. International Criminal Justice Review, 17, 304-324.

Goosby, B. J., J. E. Cheadle \& C. Mitchell. 2018. Stress-Related Biosocial Mechanisms of Discrimination and African American Health Inequities. Annual Review of Sociology, 44, 319-340.

Hancox, D. 2018. Inner City Pressure. The Story of Grime. London: William Collons.

Henrich, J., S. J. Heine \& A. Norenzayan. 2010. Most people are not WEIRD. Nature, 466, 29.

Holbrook, C. 2018. Concerts May Soon Be Using Facial Recognition Technology For Tickets. MixMag 8 May. https://mixmag.net/read/concerts-may-soon-be-using-facial-recognition-technology-for-

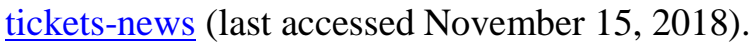

International Data Corporation. 2018. Worldwide Semiannual Smart Cities Spending Guide. Framington, MA: International Data Corporation.

Kilbourne, A. M., K. Beck, B. Spaeth-Rublee, P. Ramanuj, R. W. O'Brien, N. Tomoyasu \& H. A. Pincus. 2018. Measuring and improving the quality of mental health care: a global perspective. World psychiatry: official journal of the World Psychiatric Association (WPA), 17, 30-38.

Kim, H. \& T. Jamal. 2007. Touristic quest for existential authenticity. Annals of Tourism Research, 34, 181-201.

Kitchin, R. 2014. The real-time city? Big data and smart urbanism. GeoJournal, 79, 1-14.

Knudsen, D. C., J. M. Rickly \& E. S. Vidon. 2016. The fantasy of authenticity: Touring with Lacan. Annals of Tourism Research, 58, 33-45. 
Lawson, T., R. Rogerson \& M. Barnacle. 2018. A comparison between the cost effectiveness of CCTV and improved street lighting as a means of crime reduction. Computers, Environment and Urban Systems, 68, 17-25.

Lewis, P., T. Newburn, M. Taylor, C. Mcgillivray, A. Greenhill, H. Frayman \& R. Proctor. 2011. Reading the Riots: Investigating England's Summer of Disorder. London: London School of Economics and Political Science.

List John, A. 2007. Field Experiments: A Bridge between Lab and Naturally Occurring Data. The B.E. Journal of Economic Analysis \& Policy, 5, 1-47.

Mapping Police Violence. 2018. 2017 Police Violence report.

Marzouk, K., M. Assel, B. Ehdaie \& A. Vickers. 2018. Prostate Cancer Anxiety in Men Undergoing Active Surveillance. Findings form a Larege Prospective Cohort Study. The Journal or Urology, 199, e136-e137.

McGowan, T. 2016. Capitalism and Desire : The Psychic Cost of Free Markets. New York: Columbia University Press.

Minton, A. 2013. "Fortress Britain." High security, insecurity and the challenge of preventing harm. New Economics Foundation.

---. 2018. The paradox of safety and fear: Security in public space. Architectural Design, 88, 84-91.

OECD. 2017. How's Life 2017: Measuring Well-being. Paris: OECD Publishing.

Ohrnberger, J., E. Fichera \& M. Sutton. 2017. The relationship between physical and mental health: A mediation analysis. Social Science \& Medicine, 195, 42-49.

Pierson, E., C. Simoiu, J. Overgoor, S. Corbett-Davis, V. Ramachandran, C. Phillips \& S. Goal. 2017. A large-scale analysis of racial disparities in police stops across the United States.

Savage, M. 2018. Thousands of Swedes are Inserting Microchips Under their Skin. NPR, All Things Considered 22 October. https://www.npr.org/2018/10/22/658808705/thousands-of-swedes-areinserting-microchips-under-their-skin? $\mathrm{t}=1541532530852$ (last accessed 15 November, 2018).

Schulkin, J., P. W. Gold \& B. S. McEwen. 1998. Induction Of Corticotropin-Releasing Hormone Gene Expression By Glucocorticoids: Implication For Understanding The States Of Fear And Anxiety And Allostatic Load. Psychoneuroendocrinology, 23, 219-243.

Smith, P. L. \& D. R. Little. 2018. Small is beautiful: In defense of the small-N design. Psychonomic Bulletin \& Review.

Snapes, L. 2018. One in five at UK festivals sexually assaulted or harrassed--survey. The Guardian. https://www.theguardian.com/music/2018/jun/18/one-in-five-at-uk-festivals-sexually-assaultedor-harassed-survey (last accessed November 15, 2018).

Stol, Y. H., M. H. N. Schermer \& E. C. A. Asscher. 2017. Omnipresent health checks may result in overresponsibilization. Public Health Ethics, 10, 35-48. 
Szmigin, I., A. Bengry-Howell, Y. Morey, C. Griffin \& S. Riley. 2017. Socio-spatial authenticity at cocreated music festivals. Annals of Tourism Research, 63, 1-11.

Taylor, M. 2011. London riots: how a peaceful festival in Brixton turned into a looting free-for-all. The Guardian 8 August. https://www.theguardian.com/uk/2011/aug/08/london-riots-festival-brixtonlooting (last accessed 15 November, 2018).

Townsend, A. M. 2013. Smart cities : big data, civic hackers, and the quest for a new utopia. New York: W.W. Norton.

Wang, Y. \& M. Kosinski. 2018. Deep neural networks are more accurate than humans at detecting sexual orientation from facial images. Journal of Personality and 18Social Psychology, 114, 246-257.

Winton, R. 2018. Coachella: Police using army of drones to boost security in wake of Las Vegas massacre. LA Times April 12, 2018. November 15, 2018).

Wu, X. \& X. Zhang. 2017. Automated Inference on Criminality Using Face images. Computing Science Repository, abs/1611.04135.

Zuboff, S. 2019. The Age of Surveillance Capitalism. The Fight for a Human Future at the New Frontier of Power. New York: PublicAffairs Books. 